\title{
Entre mídia e comunicação: origens e modalidades de uma dicotomia nos estudos da área ${ }^{1}$ \\ Between media and comunication: modes e origins of a dichotomy in current research
}

Luis Mauro Sá Martino ${ }^{2}$

Resumo Embora as palavras "mídia" e "comunicação" muitas vezes apareçam de maneira indistinta nos estudos da área, em termos epistemológicos essa relação talvez não seja óbvia. Este texto propõe que, embora tomadas como sinônimas, cada uma dessas expressões revela um posicionamento epistemológico, discutido a partir de três aspectos: (a) entre as noções de "mídia" e "comunicação" como recorte de estudos; (b) entre demandas acadêmicas e de mercado na formação das teorias; (c) entre a palavra "comunicação" e sua utilização como operador epistemológico delimitador de uma área. Essas tensões são pensadas a partir dos referenciais de pesquisa da epistemologia da comunicação.

Palavras-chave: Teoria da comunicação; epistemologia; universidade; genealogia.

\begin{abstract}
Although the notion of 'Communication Theory' might be intuitionally grasped as related to 'Communication', this relationship might not be as obvious as it seems. This paper suggests that there is an assimetry between 'Communication' and its theories, which emerges from three main tension points: (a) between theory and technical skills in undergraduate courses; (b) between 'media' and/as 'communication' as the subject of studies, from which derives (c) between the word 'communication' and the a concept of 'communication'. These elements are discussed against the background of contemporary epistemological research.

Keywords: Communication theory. Epistemology. University. Genealogy.

\footnotetext{
${ }^{1} \mathrm{O}$ autor agradece aos pareceristas anônimos pelos apontamentos, de grande valia para modificações no texto.

2 Faculdade Cásper Líbero. São Paulo, SP, Brasil.

E-mail:lmsamartino@gmail.com
} 


\section{Introdução}

Sugerir, no título do trabalho, uma diferença entre "meios" e "comunicação" pode parecer um contrassenso dentro de uma área de estudos que, ao longo de mais de um século, se dedicou e dedica exatamente a lidar com os "meios de comunicação". Mais ainda quando se observa que o vocabulário da área tende a tratar os termos como sinônimos ou intercambiáveis, junto com outras expressões próximas.

Se, no limite do óbvio, as "teorias da comunicação" estariam evidentemente ligadas ao estudo da "comunicação", o problema aparece quando se lança um olhar mais atento à especificidade de cada teoria. $\mathrm{E}$, nesse momento, vemos um conjunto díspar de teorias e conceitos endereçados a problemas e objetos dos mais variados, reverberando posições de inúmeras outras áreas do conhecimento, definidos ora como "comunicação", ora como "mídia”.

Como recorda Paiva (2008, p. 2), a "tradução" de "comunicação" por "mídia" "tende a comprimir apressadamente todos os sentidos da Comunicação", e, com isso, "neutraliza a complexidade cognitiva e agregadora do fenômeno comunicativo, que deve ser entendido em suas relações dinâmicas com a sociedade e a cultura".

No entanto, cada uma dessas expressões, para além de seu uso comum, indica posições epistemológicas nos estudos da área. Falar em uma "teoria dos meios" não é necessariamente falar em uma "teoria da comunicação", apesar das relações semânticas que se pode construir entre os termos. Em outras palavras, quando se pensa em "teoria da comunicação" em sua dimensão epistemológica, parecem existir duas principais apropriações da ideia: a primeira fecha seu foco nos "meios de comunicação" ou "estudos de mídia”, enquanto a outra trabalha comunicação como "relação", com escopo diferente.

Além de uma divisão conceitual, é possível observar isso quando se examina a construção de pesquisas e teorias em circulação na área, como feito em outros momentos (MARTINO, 2009, 2010, 2015). O cenário ao qual se chega, nessa observação, é um questionamento das 
relações entre "meios" e "comunicação", ou da noção de que toda "teoria da comunicação" está ligada a uma "teoria das mídias".

O que se estuda quando alguém se dedica às teorias da comunicação?

Esta pergunta, formulada de maneiras diversas por vários pesquisadores - França (2001), L. C. Martino (2004, 2007), Sousa e Geraldes (2009), Martino (2009, 2010) ou Quiroga (2015) -, orienta um problema que demandaria, para sua resposta, o exame das teorias da área acompanhado de uma metarreflexão a respeito das possibilidades epistemológicas de considerar o vínculo de pertinência entre uma "teoria da comunicação" e a área de comunicação - tomando como premissa que os operadores epistemológicos são responsáveis, ainda que de maneira parcial, pela delimitação de uma área do saber.

Nesse ponto, Torrico Villanueva (2004, p. 11) menciona a "debilidade epistemológica” da comunicação, que, embora seja às vezes entendida como um "espaço de confluências", não resolveu ainda alguns de seus problemas de identidade.

De certa maneira, como sugere Felinto (2011) - ver também a discussão aberta por Pimenta (2011) e Ferreira (2012) -, a ausência dessa definição entre o "midiático" e o "comunicacional" se reflete tanto na problemática epistemológica quanto na definição, à beira do prosaico, de responder à pergunta “o que você estuda?” em comunicação. Se, como indica o autor, em alguns ambientes acadêmicos, a resposta "estudos de mídia” pode fornecer uma resposta satisfatória, é forçoso observar que, mesmo nos espaços anglo-saxônicos, essa definição não segue contornos absolutamente nítidos.

Sem entrar na discussão específica desses modos de entendimento ou dos autores que os sustentam, como feito anteriormente, o caminho aqui é diferente. O que se procura é delinear algumas razões constitutivas dessa divisão, focalizando no que parece ser sua gênese. Enquanto, por exemplo, Ferrara (2016) trabalha a distinção em termos epistemológicos, propondo que "mídia" não esteja necessariamente relacionada com "comunicação", aqui a busca articula a questão epistemológica em termos de uma genealogia do pensamento teórico - não em uma 
"história das teorias", observe-se -, possibilitando encontrar algumas linhas que sustentam essa formação.

Ou, em uma pergunta, de que maneira, na formulação epistemológica de base na formulação da área, se formou essa dupla perspectiva que, até hoje, tem ressonâncias em sua organização, modularidade e organização, como sugerem inúmeros autores (L. C. Martino, 2001; Braga, 2001, 2010, 2014; Gomes, 2003; Lopes, 2003, 2007; Ferreira, 2003; Signates, 2013)?

Sugere-se aqui que essa dicotomia epistemológica emerge de três principais tensões, ainda não resolvidas, presentes na área e a partir das quais o texto se desenvolve: (1) a indefinição entre o estudo da "materialidade da tecnologia" ou dos "fenômenos comunicacionais" como perspectiva da área, uma indefinição ancorada, entre outros fatores, nas (2) demandas universitárias e institucionais, que ora privilegiam a questão "técnica" e "profissional", ora voltam-se para questões "teóricas", algo relacionado com (3) a noção de "comunicação”, que já traz em si uma vasta possibilidade de ressonâncias e interpretações.

\section{0 problema da materialidade da mídia}

Uma epistemologia da comunicação talvez deva enfatizar, em primeiro lugar, o aspecto "comunicação" para depois mencionar a questão dos "meios" e da "tecnologia". Este último aspecto parece ser uma modalidade específica de um fenômeno relacional, a "comunicação", mais amplo e difícil de definir do que uma "mídia" - conceito, por sua vez, igualmente fluido, mas que parece apresentar contornos um pouco mais nítidos nas pesquisas da área.

Vale, nesse sentido, retomar a proposta de Verón (2013) no que se segue.

Certamente seria possível traçar elementos comuns, diferenças e sobreposições entre as noções de "mídia” e "comunicação". No entanto, a observação das questões de uso envolvendo um e outro conceito sugerem diferenças importantes. Uma breve diferenciação se faz necessária na medida em que, ao se trabalharem as questões de identidade e 
diferença nos ambientes digitais, a distinção entre "mídia” e "comunicação" será sublinhada de maneira importante.

O termo "mídia" pode ser encontrado em mais de uma pesquisa como sinônimo de um determinado aparato de caráter artificial produzido dentro de um contexto histórico, econômico e social por intermédio do qual se estabelecem relações - e o uso de "intermédio" é apenas um reforço da perspectiva de "estar no meio" - entre as instâncias ligadas pela "mídia".

Evidentemente, a natureza da ligação midiática está diretamente vinculada ao processo comunicacional em uma articulação complexa, sem possibilidade de redução alguma de parte a parte. Sem entrar em uma discussão pormenorizada do conceito - remete-se a Baitello (2000) -, pode-se observar algumas confluências de sentido a partir da definição consagrada pelo uso na área.

O termo "mídia", neste caso, parece se referir, com pouca problematização, a um conjunto de "meios de comunicação", de "massa" ou "digitais", destacados sobretudo por se tratarem de dispositivos tecnológicos englobados, por vezes, em um âmbito institucional no qual "mídia" ganha também o significado de "empresa de comunicação". Nas duas concepções, como aparato e como instituição, é possível observar a acentuação unilateral de uma dimensão que parece por vezes prescindir do humano e/ou do social como princípio, contexto e fim.

É possível observar algumas vezes, em determinados pontos do discurso epistemológico da área de comunicação, uma certa tendência a destacar a mídia do conjunto dos processos comunicacionais, de maneira a torná-la o elemento agenciador das ações e condições de realização de determinados fatos. Perde-se, com isso, a perspectiva de que os elementos tecnológicos, apesar de não serem de modo algum "neutros" - posto que se trata de elementos atravessados por vetores decorrentes de suas condições sociais de produção e existência -, não ganham existência se não quando de sua integração às ações humanas, não tendo, ao menos por enquanto, nenhuma possibilidade de real autonomia. 
Quando se estuda uma "mídia” isolando-a de suas condições de produção e uso, ou, em outras palavras, da teia de processos sociais nos quais ela está enredada, o resultado é a formação de uma espécie de ontologia da mídia, com a atribuição a ela, em maior ou menor escala, de uma capacidade agenciadora. Isso pode se traduzir por vezes em um discurso eivado de afirmações como "a mídia faz isto", "este aplicativo faz...", "este aparelho faz..." tomadas em sentido estrito e desprovido das ressonâncias humanas a eles atrelados.

Nesse aspecto, mesmo a observação assistemática no cotidiano empírico da pesquisa em comunicação, em particular em certas instâncias de formação, mostra a construção de discursos epistemológicos interessados não nos processos de articulação entre mídias e processos sociais ou nas relações humanas em ambientes digitais, mas nos "efeitos" das mídias digitais sobre determinados aspectos da vida humana, ecoando algumas das origens da investigação em comunicação de massa ainda no século XX. Sem negar as possibilidades desse tipo de abordagem, vale questionar em que medida não seria necessário, ao se estudar as mídias digitais, observar na sua interseção com os processos comunicacionais algo para além de um aparato técnico agenciador de "efeitos", mas de uma relação dinâmica e contraditória.

Essa concepção de uma ontologia da mídia revela-se igualmente na estipulação de uma determinada temporalidade marcada pelo advento de determinadas tecnologias, deixando-se de lado não apenas as dimensões, os fluxos e as contradições de sua incorporação ao cotidiano, mas também as desigualdades presentes nesse processo. Essa perspectiva, por seu turno, pode ser identificada em marcações de caráter temporal na qual se definem rupturas cronológicas, quando não sociais ou históricas, a partir do aparecimento de determinado meio ou dispositivo técnico. Em alguma medida, esse tipo de procedimento aponta para um discurso de mudança absoluta, objetivado em discursos reivindicatórios de um eterno recomeço a cada nova invenção - "este aplicativo mudou tudo" -, mais próximo de estratégias de divulgação do que propriamente de um escrutínio crítico. 
Ao mesmo tempo, o contradiscurso que atribui aos aparatos midiáticos pouca ou nenhuma importância, como se seu surgimento não se ligasse a nenhuma trama social, parece ser igualmente redutor no sentido de eliminar as relações existentes entre os seres humanos e a cultura por eles produzida - e que igualmente nos produz.

O rebaixamento dos ambientes digitais a um fenômeno de menor importância diante de outros parece acarretar, por seu turno, em um fechamento proposital às mudanças efetivamente em curso - sob a forma de uma talvez correta negação da causa ou da causalidade, deixa-se de lado as consequências e derivações de um determinado fenômeno.

Dito de outra maneira, a concepção de uma ontologia da mídia tende, em uma espécie de desvio semântico que talvez identifique relações oblíquas também em sua concepção, a responsabilizar o aparato tecnológico ou institucional por ações humanas. A ideia de que "tudo mudou” por conta das mídias digitais, tanto quanto sua correlata negativa, a perspectiva de que "nada mudou" apesar delas, tomam igualmente a mídia como elemento central, esvaziando o sentido da origem social de suas formas, linguagens e discursos.

É a incorporação dos dispositivos técnicos e tecnológicos nos processos sociais que lhes dá algum tipo de sentido, a partir do qual é possível articulá-los no conjunto desses mesmos processos. Parece necessário, nesse aspecto, sublinhar que a relação entre as mídias e os processos sociais não ocorre em termos de uma determinação de parte a parte seria igualmente complicado defender a autonomia dos processos sociais em relação aos meios utilizados para a configuração de suas relações -, mas em uma complexa dinâmica tensional entre seus elementos.

Isso parece ser o suficiente, ao mesmo tempo, para que se pense na especificidade desse tipo de diferença - veja-se o estudo de Trivinho (2007) sobre a "dromocracia" na cibercultura. Some-se a isso a possibilidade não apenas de leitura, mas também de compartilhamento, remixagem, transformação e comentário às mensagens em circulação para se compreender que, nos ambientes digitais, os processos de apropriação obliteram qualquer linearidade, lógica ou previsibilidade. 
Desse modo, seria talvez temerário pensar as mídias fora de sua relação potencial e potencializadora, mas também dependente, de processos derivados estritamente da prática humana. Trata-se de observar a centralidade do humano nos processos de comunicação, sem deixar de lado, evidentemente, todas as pesquisas etológicas responsáveis por revelar processos de sentido observáveis em certos animais, mas reiterando, por questões metodológicas, esse elemento.

\section{Entre a técnica midiático-profissional e a teoria no espaço universitário}

Escrevendo ainda nos anos 1980, Venício Lima (1983) indicava uma "crise de identidade" dos cursos de comunicação decorrente do que seria possível entender como um problema epistemológico relacionado à própria definição de quais seriam os parâmetros de um curso com esse enfoque. Não seria talvez exagero indicar que essa "crise de identidade" identificada naquele momento se prolonga até a atualidade, parecendo ter se espraiado para toda a chamada área de comunicação.

$\mathrm{O}$ argumento de Lima, secundado por outros autores que se debruçavam sobre a problemática do ensino de comunicação, como Noetti (1972) ou Lins da Silva (1979), derivava de uma oscilação corrente no foco dos cursos.

De um lado, uma matriz de caráter "técnico" ou "tecnicista", visando sobretudo à formação de profissionais aptos a atender às demandas de um mercado profissional pautado em um modelo de grandes empresas. De outro, uma matriz "humanista" ou "teórica" que entendia o curso de comunicação como o espaço específico de formação de pesquisadores e estudiosos capazes não apenas de pensar criticamente os fenômenos comunicacionais, mas também envolver-se em trabalhos de investigação científica.

Da ausência de articulação que pudesse efetivamente resolver esse dilema resultava um problema já identificado desde o início dos anos 1970 - e, portanto, logo após a institucionalização dos cursos de “comunicação 
social" em 1969: a ausência de parâmetros epistemológicos a partir dos quais pudesse ser desenvolvido um ramo do conhecimento alicerçado em elementos básicos constitutivos de uma ciência, a delimitação de um conjunto de fenômenos dentro de uma visada específica que constituísse uma trama de pesquisas com propósito - e segue-se, aqui, a perspectiva de Sodré (2014, p. 106) em relação a essa disposição do fazer acadêmico.

A institucionalização da área em termos de ensino universitário parece ter precedido sua fundação epistemológica. Um indício desse fenômeno, por exemplo, é a ausência quase total de uma bibliografia sobre comunicação anterior aos cursos universitários. De fato, excetuando-se os trabalhos de Décio Pignatari (1967), voltados para questões relacionadas ao design e à teoria da informação - resultantes, em alguma medida, de sua atividade poética -, e de Gabriel Cohn (1969), dentro de uma perspectiva vinculada à teoria crítica, não havia sequer uma bibliografia sobre comunicação disponível para o ensino universitários no Brasil.

Os livros teóricos sobre comunicação escritos por Vellozo (1969), Sá (1973) e Beltrão (1973), por exemplo, são declaradamente resultado de aulas em cursos de graduação, transformados em livros para uso novamente em sala de aula. Sem discutir a validade desses trabalhos e sua contribuição ao pensamento da área, é interessante notar que seu surgimento não apenas tenha atendido a uma demanda universitária, mas também indiquem, em si, a ausência de uma bibliografia anterior que pudesse sugerir o interesse nesse objeto de estudos.

De fato, ao que tudo indica, no caso brasileiro, a "comunicação" não parece ter despertado o interesse de pesquisadores antes da fundação dos cursos de comunicação, centrados nas profissões e nos meios. Ao contrário, nota-se a existência de alguns poucos trabalhos ligados à sociologia ou manuais técnicos.

Apesar dessa ausência de claridade epistemológica inicial, a consolidação dos cursos de comunicação foi bastante rápida, o que parece ter acentuado o conflito gerador da "crise de identidade" apontada por Lima (1983) e ecoada, 30 anos depois, por Sodré (2014): enquanto a 
estrutura institucional dos cursos era regida pelas habilitações voltadas para a formação profissional e para o mercado de trabalho, sua base epistemológica voltada para a "comunicação" era fragmentada dentro de uma pletora de abordagens oriundas de inúmeros campos do saber. Seguindo Vizer (2011, p. 83), é possível assinalar que "quando uma disciplina expande tanto seus interesses e seu campo de problemas, condicionada à pressão social e econômica das mudanças tecnológicas” e, ainda assim, procura "manter uma perspectiva 'humanística', se vê submetida a tensões insuportáveis".

Essa dicotomia parece ter se aprofundado nos anos seguintes e mesmo se ampliado na medida da expansão dos cursos universitários, que se desenvolvem muito mais ao redor das habilitações específicas, recordando ao mesmo tempo sua origem profissional e projetando os questionamentos epistemológicos. Nesse sentido, talvez fosse possível entender as diretrizes curriculares que transformam em cursos as habilitações profissionais como resultado desse processo de configuração da "comunicação" em torno de atividades profissionais e/ou tecnologias. Aliás, na prática acadêmica, isso é visível no discurso da área: ninguém se forma em "comunicação", mas se formam jornalistas, publicitários, relações-públicas e assim por diante.

Em certa medida, a área de comunicação, desenvolvendo-se a partir e ao redor dos cursos universitários, de alguma maneira herdou e ampliou essas problemáticas, das quais talvez derivem certos questionamentos que periodicamente vêm à tona no sentido de colocar as questões fundamentais do que define o saber comunicacional em si.

O surgimento e a consolidação dos cursos de pós-graduação, nos anos 1980, e seu crescimento nos anos 2000 parecem recolocar a questão ainda com mais força na medida. Esses espaços, orientados não mais pela demanda imediata de um mercado profissional - embora seja possível falar em um "mercado acadêmico", isso seria desviar o foco desta discussão -, mas pela formação de pesquisadores, são o local onde se colocam continuamente questões de ordem epistemológica que nascem, ou se convertem, em problemas práticos. 
A experiência de orientação oferece indícios do cotidiano: perguntas recorrentes como "Minha pesquisa é em comunicação?" ou "Meu objeto é da comunicação?” sugerem um problema mais profundo: como delimitar, de fato, se uma pesquisa é de "comunicação"? A escolha do "referencial teórico", em particular, coloca pesquisadores diante do que parece ser o coração do problema: quais teorias são "da comunicação"? De onde se podem formular conceitos de "comunicação"? Ou se trata, por outro lado, de estudar os "meios de comunicação" a partir de referenciais de outras áreas do saber?

Os referenciais, vindos de áreas diversas, muitas vezes levam pesquisadores e pesquisadoras da comunicação a se enveredarem por outros espaços do saber na busca de operadores epistemológicos que serão, em seguida, "aplicados" aos objetos eleitos como "comunicação". Evidentemente, não há aqui sugestão de generalizar, mas apenas de ilustrar um argumento a partir de situações práticas.

Não seria ocioso lembrar, com Wolton (2001) ou Sodré (2014), que a definição de "comunicação" em si deriva do aporte teórico dado, responsável por sua delimitação. Cada área do saber se apropria dos fenômenos da comunicação a partir de seu olhar específico, construído dentro da história da disciplina, cada um deles contribuindo a seu modo para ampliar o entendimento do assunto.

Isso gera ao menos dois problemas.

Em primeiro lugar, o fato do objeto comunicacional estar ligado ao olhar que o constitui pode conduzir a uma tautologia: se existe um olhar "antropológico" ou "sociológico" sobre a comunicação, qual seria a especificidade de um olhar "comunicacional" sobre a comunicação? O que justificaria, por exemplo, a inclusão ou exclusão de uma pesquisa em um programa de pós-graduação em comunicação?

Ao mesmo tempo, em que medida se pode falar em uma área de comunicação uma vez que o núcleo de sua categorização não é formado por definições específicas, mas por um objeto constituído na justaposição de saberes que, além de serem provenientes de outros campos, não são apropriados e reconstituídos, mas "aplicados" a objetos que se supõe 
serem “comunicacionais"? Não é o caso, aqui, de propor uma definição específica de comunicação ou sequer pleiteála, mas indicar, com Braga (2014), a necessidade de tensionar uma diversidade que, em geral, se transforma em dispersão.

A definição taxonômica da pertinência de uma pesquisa não deriva, portanto, de um preciosismo na busca de uma definição, mas da perspectiva de uma axiologia dos elementos classificatórios em jogo dentro de qualquer busca epistemológica que define a própria área.

\section{Modulações entre a palavra e o conceito de comunicação}

A polimorfia dos fenômenos comunicacionais parece se constituir em outro obstáculo epistemológico à definição dos contornos de uma área de estudos. Há, aqui, a necessidade de sugerir uma distinção terminológica que talvez possa contribuir para situar a questão. Seguindo a problemática delineada por Paiva (2008), Verón (2013) e Sodré (2014) a respeito das relações entre a palavra e o conceito de "comunicação", vale procurar algumas definições e tensionamentos a respeito de ambos.

Vários autores salientam a perspectiva de "comunicação" a partir de uma base etimológica, procurando encontrar nas raízes do termo algumas pistas para definir o que poderia ser o recorte de uma área de investigação. Em geral, esse aporte tende a sublinhar o aspecto relacional dos fenômenos comunicacionais, estabelecendo uma base entre as diversas palavras dentro de um campo semântico próximo, como "comunhão", "comum", "comunidade" e assim por diante.

Merloo (1973, p. 168) chega a traçar uma relação entre a noção de "comunicação" e seu radical munis ao conceito de munia, que traduz por "serviço", e se torna objeto de reflexões mais detalhadas em Esposito (2005), Paiva (1999), Yamamoto (2014) e Sodré (2014). De fato, algumas das ambiguidades presentes no estabelecimento de um conceito de comunicação podem derivar, como indica Lima (1983), da ambiguidade do termo, que encerra, em sua raiz de "tornar comum”, tanto as ideias de "transmissão" quanto de "compartilhamento", elementos 
que se tornariam, na visão do autor, os pontos de vista dominantes na construção de modelos comunicacionais, ora focados no trabalho de transmissão (de natureza unidirecional), ora no ato de compartilhar (de caráter dialógico).

No entanto, se é conhecido o sentido e a etimologia da palavra e, evidentemente, sem deixar de lado a contribuição que esse tipo de investigação oferece, talvez seja possível arriscar outro problema: se sabemos o que o termo significa, as dificuldades parecem emergir na transformação da palavra em um conceito, entendido como um operador epistemológico capaz de dar conta de uma parcela relativamente definida de fenômenos que, apreendidos pela palavra, perdem em sua realidade dinâmica para ganhar em termos de inteligibilidade.

Se é possível rastrear uma origem da palavra "comunicação", sua operacionalização como conceito capaz de dar conta de determinada realidade parece ser muito menos simples. O conceito, em sua interseção oblíqua com o fenômeno para torná-lo operacional, não prescinde de limites capazes de oferecer alguma definição ao que está sendo estudado. É nesse sentido que a "definição" de comunicação parece se separar de um "conceito" de comunicação: a ideia de um conceito se apresenta como interligada a uma perspectiva de pesquisa por conta de sua definição. Valeria, nesse sentido, perguntar não apenas "o que significa "comunicação" ou "quais são os sentidos da palavra na área”, mas que tipos de fenômenos são conceituados como "comunicação".

Indicar a polissemia da resposta talvez não seja ocioso. De algum modo, como indica Vizer (2011, p. 98), os estudos de comunicação tendem a delimitar o fenômeno e apreender essa noção principalmente a partir de matrizes que privilegiam o social ou a linguagem (sem necessariamente aqui se falar em "sociologia” ou "linguística”, mas em aportes mais ou menos originários e voltados para essas áreas), em perspectiva próxima ao que argumentam Breton e Proulx (2002) ou mesmo, apesar da diferença de perspectivas, Miege (2000) e Wolton (1998).

Se os estudos de comunicação se desenvolvem em torno de uma perspectiva relacional como prática social voltada para a construção de 
sentidos, como sugerem, entre outros, Verón (2013), Muchielli (1991), Wolton (2011) ou Vizer (2011), então, sem deixar de lado as diferenças entre esses autores, é possível questionar em que medida é possível estabelecer um conceito de "relação" que destaque o enfoque propriamente "comunicacional" uma vez que a vinculação do relacional com a construção de sentidos também é objeto, por exemplo, dos estudos da antropologia ou da linguística.

Embora o ambiente acadêmico europeu e norte-americano pareça ter resolvido parcialmente a questão optando pelo termo "mídia" ou o antigo "comunicação de massa” para definir a área, vale notar aí também certas ambiguidades. Wright (1968) e DeFleur (1976) ou, mais recentemente, os livros-texto de Severin e Tankard (2001) e McQuail (2005), por exemplo, resolvem a questão indicando a "comunicação de massa" como objeto de conhecimento, desdobrando-se nas diversas mídias - TV, rádio, cinema - como objeto de estudos.

Vale observar, no entanto, que isso não significa eliminar a polissemia da noção de "comunicação", uma vez que estudos semelhantes, tanto antigos (Dance, 1973; Littlejohn, 1976; Mortensen, 1980) quanto mais recentes (Lazar, 1996; o mencionado Severin e Tankard, 2001; Crowley e Mitchell, 1994; e Holmes, 2005), utilizam a expressão "teoria da comunicação" para se referir, de fato, à "mídia”, "comunicação de massa” ou, em menor medida a partir de 1990, às mídias digitais.

O ambiente ibérico também não parece oferecer uma divisão específica, como sugerem os trabalhos de Santos (1992), Freixo (2012) ou, anteriormente, a coletânea de Moragas Spa (1981), que definem como "teoria da comunicação" um foco nos então chamados "meios de massa".

O campo semântico coberto por "estudos de mídia”, portanto, equivale apenas parcialmente à "teoria da comunicação"; ao mesmo tempo, como indicado, mesmo a perspectiva de "estudos de mídia”, por conta da polissemia conceitual de "mídia" nos estudos de comunicação, não parece necessariamente contribuir para a definição do objeto, mas apenas para o que aparenta ser uma resolução imediata de uma 
problemática epistemológica que, no entanto, não subsiste a um escrutínio mais amplo.

A passagem da palavra "comunicação" a um conceito de "comunicação", como observado, não parece ser algo claro nos estudos da área: ao contrário, por trás do que poderia ser entendido como um elemento de transparência quase evidente ao se falar de "estudos de comunicação", a perspectiva parece se direcionar muito mais para a ideia de "estudos dos meios" do que propriamente para um fenômeno comunicacional que possa ser separado das mídias.

Isso não significa, de maneira nenhuma, que essa passagem não seja objeto de pesquisas de excelência. A interlocução entre Braga (2011), Marcondes (2010, 2012) e Ferrara (2013) desenvolvida, entre outros espaços, no GT Epistemologia da Comunicação da Compós parece se encaminhar exatamente na busca de uma conceituação de "comunicação" a partir da qual algumas dessas problemáticas possam ser rearticuladas.

O propósito, nesse sentido, não é evidentemente sugerir qualquer tipo de exclusividade à comunicação como disciplina, mas pensá-la em sua especificidade. $\mathrm{O}$ assimétrico equilíbrio entre a comunicação como "disciplina” e como "campo", retomando uma definição de Braga (2012), pode resultar na constituição de um aporte que, pensando a partir de Sodré (2014), poderia ser entendido como algo que conserva características de disciplinas justapostas sem proporcionar um elemento de diálogo entre elas.

Braga (2010) indica como, muitas vezes, o elemento comunicacional se apresenta como o que denomina um "epifenômeno" de uma pletora de processos sociais diversos a partir dos quais o elemento comunicacional, mesmo em toda sua diversidade, não é apreendido senão como um dado formado a partir desses processos, sem a centralidade que o recorte como objeto, retomando L. C. Martino (2007), poderia pressupor. A busca pelo que Signates (2013) indica como o "especificamente comunicacional" nem sempre aparece como um problema epistemológico no campo. À transparência suposta da palavra corresponde uma 
opacidade do conceito a partir da qual a fundamentação epistemológica da área se constitui como um tensionamento constante.

\section{Considerações finais}

A abordagem de uma área do conhecimento tende a trazer à tona os fios e tramas que a constituem em sua dinâmica. Com a área de comunicação isso não é diferente e o trabalho cotidiano no ambiente de pesquisa e investigação pode sugerir a percepção de certas problemáticas que, localizadas em alguns pontos fundamentais de sua epistemologia, terminam por se espalhar em quase toda a constituição dos saberes produzidos nessa área.

Algumas das tensões apontadas neste texto - a questão da materialidade da mídia, as demandas institucionais e profissionais, a polissemia do conceito - tendem a se manifestar, em escala consideravelmente maior, quando se pensa não apenas em termos da constituição identitária da área, como faz L. C. Martino (2001), mas também em vários outros aspectos. A definição de um objeto empírico de pesquisa, que tende a se subordinar às problemáticas do objeto de conhecimento de uma área, por exemplo, pode se tornar mais complicada na medida em que a parametrização da relação entre os dois termos não é clara.

$\mathrm{O}$ que se buscou aqui, mais do que tomar parte em qualquer das dicotomias indicadas - o que seria, por seu turno, um fechamento ao ato de questionar, elemento presente nas inquietações de origem deste texto -, foi estabelecer três pontos, na gênese das teorias da comunicação, nos quais esses elementos podem encontrar algumas de suas origens.

Se, como notado no início, a noção de "comunicação" está diretamente ligada ao conceito de "meios", sobretudo por conta de décadas de estudos sobre os "meios de comunicação", por outro lado as perguntas subjacentes a esse tipo de estudo - quais "meios"? Qual "comunicação”? Como relacioná-los? -, se observadas mais de perto, mostram que a aparente obviedade da relação não resiste a uma investigação mais elaborada sem exibir algumas de suas profundas contradições e assimetrias, presentes como tensão original nos fundamentos da área. 
Pensar esses questionamentos na abertura para novas perguntas talvez possa contribuir mais do que esboçar uma resposta para trabalhar as problemáticas teóricas da comunicação. Algo que, muito além do que poderia ser uma mera elaboração conceitual, se reflete nos problemas cotidianos do ensino e da pesquisa.

\section{Referências}

BRAGA, J. L. Comunicação, disciplina indiciária. Matrizes, n. 2, p. 73-88, abr. 2008. Disciplina ou Campo? In: SIGNATES, L.; PIMENTA, F. J. P.; FERREIRA, J.

Estudos de Comunicação. São Leopoldo: Unisinos, 2012.

BRAGA, J. L. Dispositivos Interacionais. In: ENCONTRO DA COMPÓS, 20, 2011, Porto Alegre. Anais... Porto Alegre: UFRGS, jun. 2011.

BRAGA, J. L. Um conhecimento aforístico. In: ENCONTRO DA COMPÓS, 23, 2014, Belém. Anais... Belém: UFPA, jun. 2014.

BRETON, P.; PROULX, S. L'Explosion de la Communication. Paris: La Découverte, 2002.

BRYANT, J.; MIRON, D. Theory and Research in Mass Communication. Journal of Communication, v. 54, n. 4, dez. 2004.

CRAIG, R. Communication Theory as a Field. Communication Theory, 9(2), maio 1999.

CROWLEY, D.; MITCHELL, D. Communication Theory Today. Standford: Standford University Press, 2000.

DANCE, F. E. X. (Org.). Teoria da Comunicação Humana. São Paulo: Cultrix, 1973.

DEFLEUR, M. Teorias de Comunicação de Massa. Rio de Janeiro: Zahar, 1976.

ESPOSITO, R. Communitas. Buenos Aires: Amorrotu, 2005.

FELINTO, E. Da Teoria da Comunicação às teorias da mídia. In: ENCONTRO DA COMPÓS, 20, 2011, Porto Alegre. Anais... Porto Alegre: UFRGS, jun. 2011.

FERRARA, L. D’A. A epistemologia de uma comunicação indecisa. In: ENCONTRO DA COMPÓS, 22, 2013, Salvador. Anais... Salvador, jun. 2013.

FERRARA, L. D’A. Exposição oral. In: SEMINÁRIO TEORIAS DA COMUNICAÇÃO, 8, 2016, São Paulo - Quinta Essencial: Pensadores da Comunicação. São Paulo: Faculdade Cásper Líbero, 10-12 ago. 2016.

FERREIRA, J. Proposições que circulam sobre a Epistemologia da Comunicação. In: ENCONTRO DA COMPÓS, 21, 2012, Juiz de Fora. Anais... Juiz de Fora: UFJF, jun. 2012. p. 1-17. 
FERREIRA, J. Questões e linhagens na construção do campo epistemológico da Comunicação. In: (Org.). Cenários, teorias e metodologias da Comunicação. Rio de Janeiro: E-papers, 2007.

FRANÇA, V. Paradigmas da Comunicação: conhecer o quê? In: MOTTA, L. G.; FRANÇA, V.; PAIVA, R.; WEBER, M. H. (Orgs.). Estratégias e culturas da comunicação. Brasília: UnB, 2001.

FREIXO, M. J. Teorias e Modelos da Comunicação e da Mídia. Lisboa: Instituto Piaget, 2012.

LAZAR, J. La science de la communication. Paris: PUF, 1996.

LIMA, V. Repensando as teorias da comunicação. In: MELO, J. M. Teoria e pesquisa em comunicação. São Paulo: Intercom: Cortez, 1983.

LITTLEJOHN, S. Teorias da Comunicação Humana. Rio de Janeiro: Zahar, 1976.

LOPES, M. I. V. Sobre o estatuto disciplinar do campo da Comunicação. In:

Epistemologia da Comunicação. São Paulo: Loyola, 2003.

MARCONDES FILHO, C. A Comunicação no sentido estrito e o Metáporo. In: ENCONTRO DA COMPÓS, 21, 2012, Juiz de Fora. Anais... Juiz de Fora: UFJF, jun. 2012.

MARCONDES FILHO, C. Duas doenças infantis da comunicação. Matrizes, v. 4, n. 2, 2010.

MARTINO, L. C. Teorias da Comunicação: muitas ou poucas? Cotia, SP: Ateliê Editorial, 2007.

MARTINO, L. M. S. Descontinuidades epistemológicas na Teoria da Comunicação: um estudo das taxonomias entre 1969 e 2011. Logos, v. 22, p. 105-120, 2015.

. O que foi teoria da comunicação? Um estudo da bibliografia entre 1967-1986.

Revista Comunicação Midiática (on-line), v. 6, p. 28-39, 2011. 4, n. 8, 2010 .

Quatro ambivalências na teoria da comunicação. Rumores. São Paulo: USP, v.

. Teoria da Comunicação. Petrópolis: Vozes, 2009.

MATTOS, M. A. Intermitências epistêmicas da Comunicação. In: PINTO, J.; SERELLE, M. Interações Midiáticas. Belo Horizonte: Autêntica, 2006.

MCQUAIL, D. Mass Communication Theory. Londres: Sage, 2005.

MIÉGE, B. O Pensamento Comunicacional. Petrópolis: Vozes, 2000.

MORAGAS SPA, M. Teorias de la Comunicación. Barcelona: Gustavo Gilli, 1981.

MORTEnSEN, G. D. Teoria da Comunicação. São Paulo: Mosaico, 1980.

MUCCHIELLI, A. Les situations de communication. Paris: Eyrolles, 1991.

PAIVA, C. Elementos para uma epistemologia da cultura midiática. Culturas Midiáticas, ano I, n. 1, p. 1-12, jul.-dez. 2008.

PAIVA, R. O espírito comum. Petrópolis: Vozes, 1999.

PERUZZO, C. K. Em busca dos objetos de pesquisa em Comunicação no Brasil. In: WEBER, M. H.; BENTZ, I.; HOHFELDT, A. Tensões e objetos da pesquisa em Comunicação. Porto Alegre: Sulina, 2002. 
PIMENTA, F. J. P. Jogos, redes sociais e a crise no campo da Comunicação. In: SIMPÓSIO NACIONAL DA ABCIBER, 5, 201 1, Florianópolis. Anais... Florianópolis: UFSC, nov. 2011. p. 1-16.

QUIROGA, T. Pensar a episteme comunicacional. 2. ed. Recife: UFPE, 2015.

SÁNCHEZ, L.; CAMPOS, M. La Teoría de la comunicación: diversidad teórica y fundamentación epistemológica. Dialogos de la Comunicación, n. 78, p. 24-38, jan.-jul. 2009.

SANTOS, J. R. Comunicação. Lisboa: Difusão Cultural, 1992.

SEVERIN, T; TANKARD, D. Communication theories. Nova York: Longman, 2001.

SODRÉ, M. A ciência do comum. Petrópolis: Vozes, 2014.

SOUSA, J.; GERALDES, E. Um saber sobre tensão: as múltiplas visões sobre a origem, o objeto de estudos e o conceito da disciplina comunicação. Razon y Palabra, v. 14, n. 67, p. 1-22, mar.-abr. 2009.

TORRICO VILLANUEVA, E. R. Abordajes y periodos de la teoria de la comunicación. Buenos Aires: Norma, 2004.

TRIVINHO, E. A dromocracia cibercultural. São Paulo: Paulus, 2007.

VERON, E. La semiosis social 2. Buenos Aires: Paidós, 2013.

VIZER, E. A. A trama (in)visível da vida social. Porto Alegre: Sulina, 2011.

WOLTON, D. Penser la communication. Paris: Flammarion, 1998.

WRIGHT, C. Comunicação de Massa. Rio de Janeiro: Bloch, 1968.

YAMAMOTO, E. I. O conceito de comunidade na comunicação. Galáxia, v. 21, n. 2, 2014.

\section{Sobre 0 autor}

Professor da Pós-Graduação em Comunicação da Faculdade Cásper Líbero, onde leciona na graduação em jornalismo e edita a Revista Líbero. Pós-doutorado na School of Political, Social and International Studies na University of East Anglia (Reino Unido). Suas pesquisas estão direcionadas, de um lado, para estudos sobre teoria e epistemologia da comunicação; de outro, à compreensão das relações entre mídia, política e religião.

Data de submissão: 01/03/2016

Data de aceite: 22/09/16 